\title{
Serially Connected Micro Amorphous Silicon Solar Cells for Compact High-Voltage Sources
}

\author{
Jiyoon Nam, ${ }^{1}$ Youngjoo Lee, ${ }^{2}$ Chang Su Kim, ${ }^{2}$ Hogyoung Kim, ${ }^{3}$ \\ Dong-Ho Kim, ${ }^{2}$ and Sungjin Jo ${ }^{1}$ \\ ${ }^{1}$ School of Architectural, Civil, Environmental, and Energy Engineering, Kyungpook National University, Daegu 41566, \\ Republic of Korea \\ ${ }^{2}$ Advanced Functional Thin Films Department, Korea Institute of Materials Science (KIMS), Changwon 51508, Republic of Korea \\ ${ }^{3}$ Department of Visual Optics, Seoul National University of Science and Technology, Seoul 01811, Republic of Korea
}

Correspondence should be addressed to Sungjin Jo; sungjin@knu.ac.kr

Received 21 July 2016; Accepted 5 October 2016

Academic Editor: Shu Seki

Copyright (c) 2016 Jiyoon Nam et al. This is an open access article distributed under the Creative Commons Attribution License, which permits unrestricted use, distribution, and reproduction in any medium, provided the original work is properly cited.

\begin{abstract}
We demonstrate a compact amorphous silicon (a-Si) solar module to be used as high-voltage power supply. In comparison with the organic solar module, the main advantages of the a-Si solar module are its compatibility with photolithography techniques and relatively high power conversion efficiency. The open circuit voltage of a-Si solar cells can be easily controlled by serially interconnecting a-Si solar cells. Moreover, the a-Si solar module can be easily patterned by photolithography in any desired shapes with high areal densities. Using the photolithographic technique, we fabricate a compact a-Si solar module with noticeable photovoltaic characteristics as compared with the reported values for high-voltage power supplies.
\end{abstract}

\section{Introduction}

Since microelectromechanical system (MEMS) actuators such as piezoelectric and electrostatic micropumps require driving voltages of tens to hundreds of volts, additional external high-voltage power sources are generally used in MEMS devices [1-3]. A direct on-board or remote power supply is needed for autonomous operation of many MEMS devices. Solar cells are desirable to be used as a self-contained high-voltage power supply for MEMS being an autonomous power source since the open circuit voltage of the solar cells can be easily scaled up by connecting cells in series [4].

Recently, high-voltage power sources based on organic solar cells have been demonstrated owing to their advantages such as the low fabrication cost and the compatibility between different organic electronic devices $[5,6]$. In order to fabricate high-voltage sources using organic solar cells, individual cells should be serially connected [7]. Various fabrication approaches for producing serially interconnected organic solar cells have been demonstrated. Lewis et al. demonstrated a high-voltage organic solar array with miniature cells interconnected in series [8]. Top electrodes were deposited and patterned through a shadow mask for making the series connections of the array. Although an open circuit voltage of $7.8 \mathrm{~V}$ and a power conversion efficiency of $0.06 \%$ were achieved in a device area of $2.2 \mathrm{~cm}^{2}$ with an array of 18 cells, the fabrication of small array devices is difficult since it is challenging to align the shadow mask with the anode. In order to achieve high voltages with a small area, direct high resolution patterning of organic active layer using photolithography techniques was introduced. Lim et al. demonstrated that the photolithographic patterning using perfluorinated resorcinarene photoresist is effective for fabricating organic solar cells, which exhibited an open circuit voltage of $90 \mathrm{~V}$ and a power conversion efficiency of $0.3 \%$ when 300 cells were connected in series [9]. This fluorinated imaging material can be used for patterning nonfluorinated organic materials including poly(3-hexylthiophene) (P3HT), which is a widely used active material in organic solar cells. However, it is still challenging to pattern other organic semiconductors by photolithography techniques since the solvents used in photolithography could damage the organic semiconductors. In order to overcome this obstacle in the patterning of organic solar cells, Niggemann et al. demonstrated an organic 
photovoltaic nanomodule using a transparent nanostructured substrate [10]. To connect cells in a scale of several hundred nanometers in series, anodes and cathodes were deposited on the vertical walls of intralamellar structures and photoactive components were sandwiched in a planar configuration between the electrodes. An open circuit voltage of $880 \mathrm{~V}$ and a power conversion efficiency of $0.008 \%$ were achieved for a nanomodule with a width of $17.4 \mathrm{~mm}$ and a length of $7.9 \mathrm{~mm}$. However, the production of lamellar nanostructure substrates as well as the fabrication of parallel solar cells with nanolamellar structures is rather difficult. All the abovementioned approaches for the fabrication of high-voltage power supplies with organic solar cells suffer from disadvantages such as the chemical incompatibility and complexity of the patterning process used in the serial connection as well as the low power conversion efficiency of the solar modules. Photolithography is a simple and well-established technique used for patterning with a high resolution and throughput $[11,12]$. Therefore, it is desirable to develop high-voltage power supplies using solar cells that are compatible with photolithography techniques and exhibit high power conversion efficiencies.

In this work, we demonstrate a compact amorphous silicon (a-Si) solar module for high-voltage power supply applications. The a-Si solar cell exhibits relatively improved solar properties as compared with conventional organic solar cells and can be easily patterned in desired shapes using photolithography techniques [13]. Unlike in the case of organic solar cells with a parallel structure, there is no constraint associated with the conventional deposition processes in the fabrication of a-Si solar cell layers since photolithographic techniques are employed, and hence the areal density can be maximized through patterning in micrometer scale [14]. Therefore, stepping up the open circuit voltage can be easily accomplished by controlling the number of interconnected solar cells. Furthermore, a fewer number of a-Si solar cells are needed in the serial connection to achieve the same operation voltage with organic solar cells, due to the relatively higher open circuit voltage obtained with the a-Si solar cells than that of organic solar cells [15]. Using photolithographic techniques, a single a-Si solar cell with a width of $450 \mu \mathrm{m}$ is fabricated with the interconnected $250 \mu \mathrm{m}$ wide electrodes patterned serially, and the whole device is fabricated in an area of $2 \mathrm{~cm}$ [2]. Without any changes of conventional fabrication process, the prepared compact a-Si solar module exhibits enhanced solar properties as compared with organic solar cells, and the prepared solar module can be used as highvoltage solar supply owing to the achieved fill factor (FF), max. power, and power conversion efficiency.

\section{Materials and Methods}

2.1. Fabrication of a-Si Solar Cell. Conventional soda-lime glass was cut in the area of $2.5 \times 2.5 \mathrm{~cm}^{2}$ followed by cleaning the substrates with acetone, isopropyl alcohol, and deionized water in a sonication bath. A hydrogenated a-Si layer and an Al-doped zinc oxide (AZO) layer were deposited by employing cluster-type plasma-enhanced chemical vapor deposition (PECVD) and sputtering for depositing the device layers in situ under high-vacuum conditions. Initially, a $500 \mathrm{~nm}$ thick AZO layer as the bottom electrode was deposited directly on the substrate at $300^{\circ} \mathrm{C}$ by sputtering. The p-type, n-type, and intrinsic a-Si layers were deposited at $250^{\circ} \mathrm{C}$ with thicknesses of $13,25.7$, and $460 \mathrm{~nm}$, respectively. A $300 \mathrm{~nm}$ thick AZO layer was deposited at $300^{\circ} \mathrm{C}$ by sputtering as the top contact layer. Finally, a $100 \mathrm{~nm}$ thick Al layer to act as the top electrode was deposited on the top AZO layer by thermal evaporation.

2.2. Fabrication of High-Voltage Solar Module. Microcells were fabricated by patterning a-Si solar cells employing photolithography and etching techniques. The top AZO layer was etched with dilute $\mathrm{HCl}$ by using a photolithographically patterned positive photoresist as an etching mask. A-Si layers were etched by reactive ion etching with radiofrequency power of $150 \mathrm{~W}$ for $30 \mathrm{~min}$ with a $\mathrm{CF}_{4} / \mathrm{O}_{2}$ (95:5) mixture using the top AZO layer as the etching mask. The bottom AZO layer was patterned employing the same process. The Al electrode with a thickness of $100 \mathrm{~nm}$ deposited by thermal evaporation was patterned through a lift-off process. SU-8 was spin-coated on top of the solar cell layers, which was patterned for serving as the encapsulation layer for each single solar cell. To serve as an interconnection electrode, $\mathrm{Cr} / \mathrm{Au}$ layers were deposited by e-beam evaporator and patterned by photolithography.

2.3. Measurements. Photocurrent and voltage measurements were performed using a Keithly 2400 source meter under one-sun illumination ( $\left.\mathrm{AM} 1.5,100 \mathrm{~mW} / \mathrm{cm}^{2}\right)$ at room temperature.

\section{Results and Discussion}

Using the thin a-Si solar cell layers, we fabricated a highvoltage a-Si solar module with a compact design. The structures of the single a-Si solar cell and the high-voltage solar module are illustrated in Figures 1(a) and 1(b). Additionally, Figure 1(c) shows detailed cross-sectional scanning electron microscopic (SEM) image of the unit device. The bottom $500 \mathrm{~nm}$ thick AZO layer and the top $300 \mathrm{~nm}$ thick AZO layer serve as the bottom and top electrodes of the a-Si solar cell, respectively, and also as the etching mask of a-Si (p-i-n) layer in reactive ion etching. The encapsulation layer of the polymeric material, SU-8, was patterned by photolithography with two via holes for forming interconnections between the gold and aluminum electrodes. The SU-8 encapsulation layer also prevents short circuits by covering the a-Si solar cell layers beneath the interconnection electrode. In order to serially interconnect the a-Si solar cells, we patterned each single cell by interchanging the top and bottom AZO electrodes. Interconnection electrodes are patterned for connecting the a-Si solar cells serially using photolithography techniques.

Before serially interconnecting the a-Si solar cells, we estimated the photovoltaic characteristics of a single a-Si solar cell (reference). Figure 2(a) shows the current density versus voltage curve and the maximum power versus voltage curve for a single a-Si solar cell. Light source irradiates from the bottom of the high-voltage module since the aluminum electrode is deposited on the top AZO layer. The aluminum 


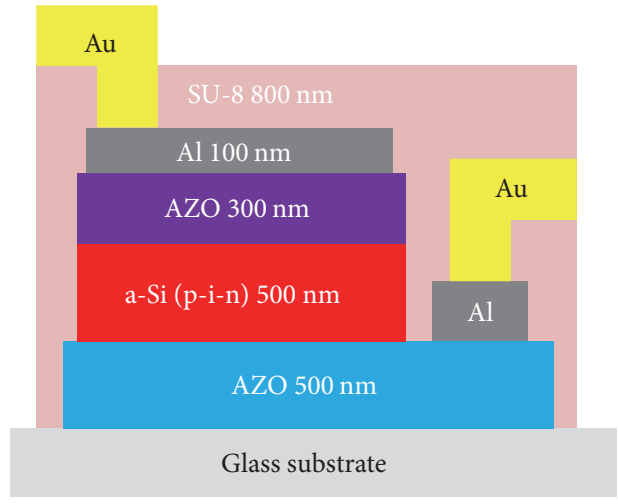

(a)

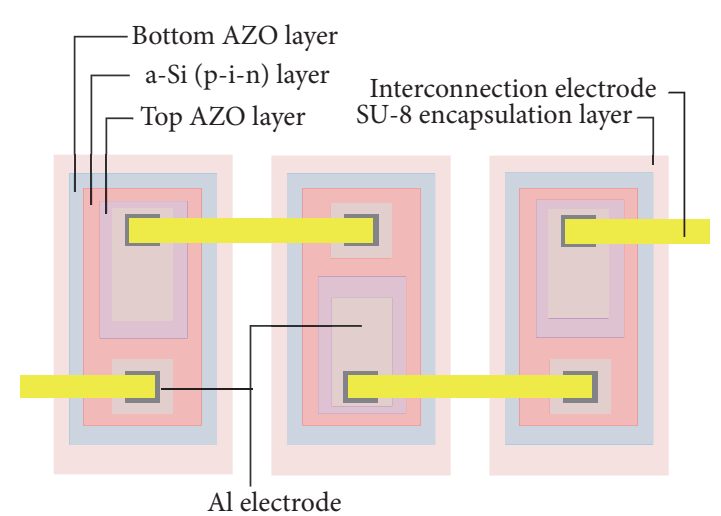

(b)

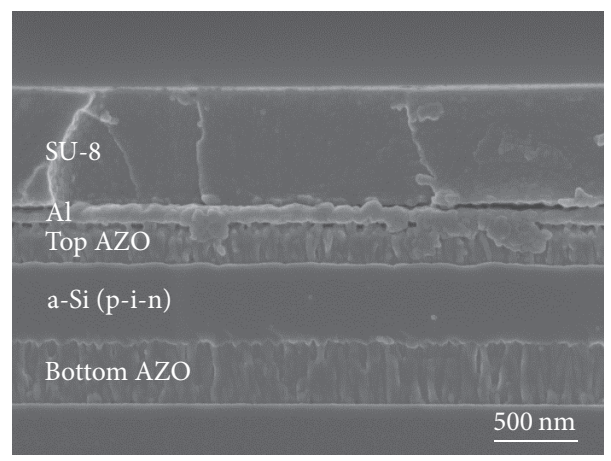

(c)

FIGURE 1: Schematic of the compact amorphous silicon solar module for high-voltage power supply applications. (a) Configuration of a single a-Si solar cell structure. (b) Top view of the interconnected high-voltage a-Si solar module with the gold electrode. (c) Cross-sectional SEM image of unit device.

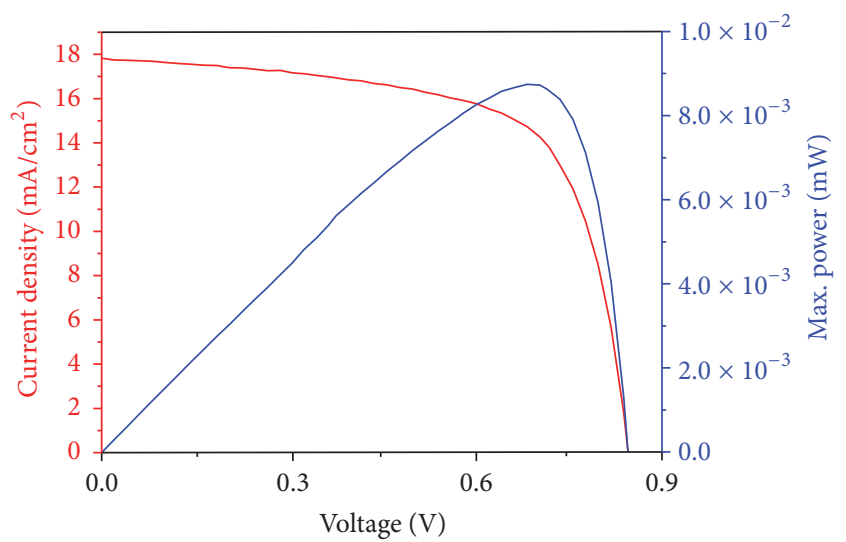

(a)

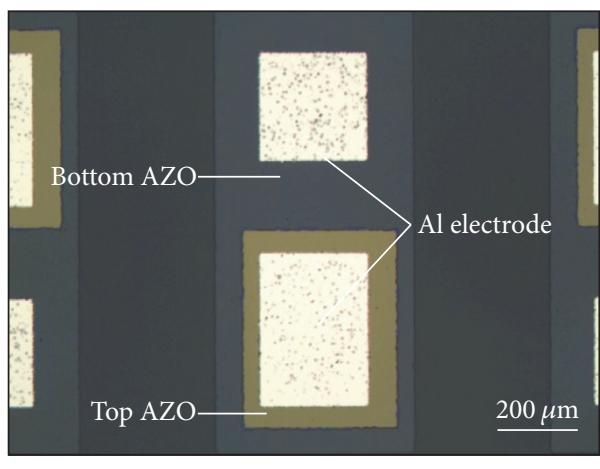

(b)

Figure 2: (a) Current density versus voltage and maximum power versus voltage curves of a single a-Si solar cell. (b) Optical microscopic image of single a-Si solar cell fabricated using photolithographic techniques.

electrode acts as a contact metal for lowering the contact resistance and a back reflecting layer for each a-Si solar cell. An open circuit voltage of $0.847 \mathrm{~V}$, short circuit current density of $17.8 \mathrm{~mA} / \mathrm{cm}^{2}$, FF of $66.3 \%$, and maximum power of $8.76 \mu \mathrm{W}$ are achieved. Figure 2(b) shows the optical microscopic image of a single a-Si solar cell patterned with a width of $450 \mu \mathrm{m}$ and a length of $1 \mathrm{~mm}$ for each single cell employing photolithography and etching techniques.

In order to increase the open circuit voltage, each single solar cell was serially connected with gold electrodes. As shown in Figure 3(a), the aluminum electrode for the bottom contact of a single solar cell is connected to aluminum 


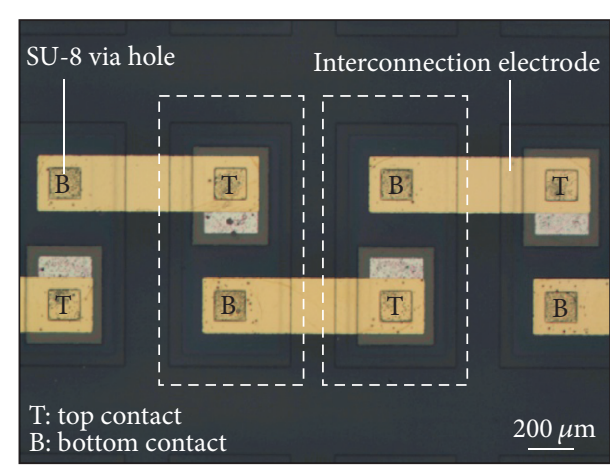

(a)

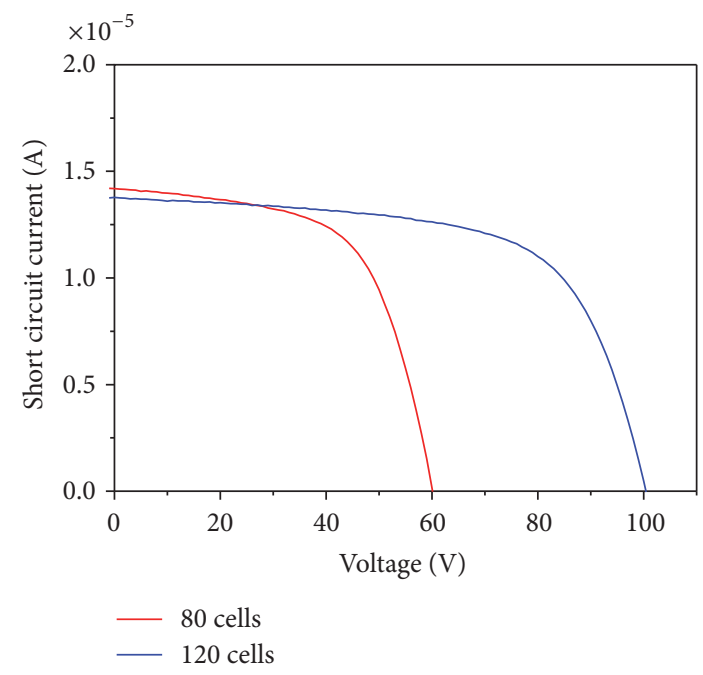

(c)

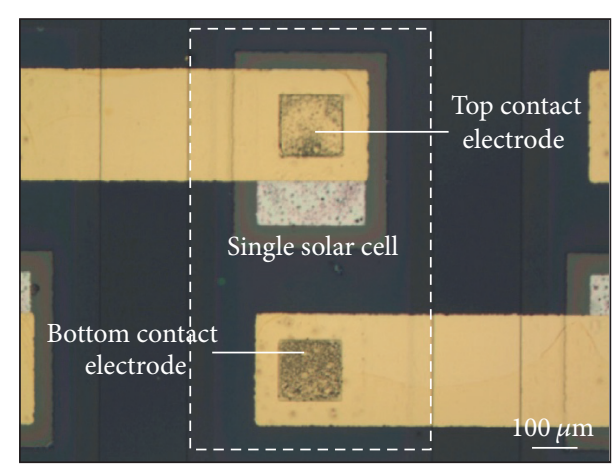

(b)

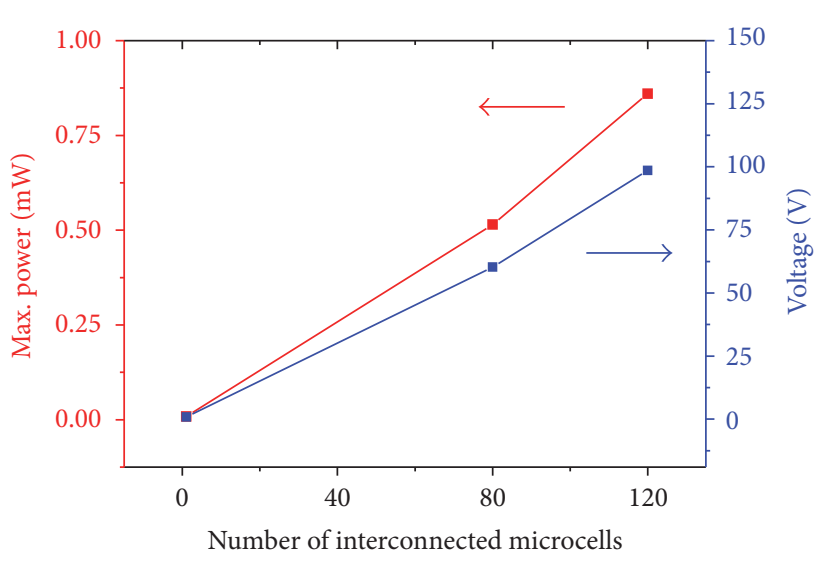

(d)

FIGURE 3: (a) Optical microscopic image of integrated high-voltage solar module. Each single solar cell is connected by serially interconnecting with the gold electrode. (b) Expanded optical microscopic image of interconnected single a-Si solar cell. (c) Current-voltage curve with respect to the number of interconnected microcells ( 80 cells and 120 cells). (d) Output power and the operation voltage with different numbers of interconnected microcells (single cell, 80 cells, and 120 cells).

electrode for the top contact of another single solar cell by interconnecting the electrode to increase the open circuit voltage. Gold electrodes are patterned on every cell serially to increase the open circuit voltage. The magnified microscopic image displays the top and bottom contacts of the a-Si solar cell (Figure 3(b)).

Within an area of $2 \times 2 \mathrm{~cm}^{2}$, we fabricated two types of high-voltage solar modules for controlling the operation voltage. Figure 3(c) shows the current density versus voltage curves for the high-voltage solar modules, which were serially interconnected with 80 cells and 120 cells. For the a-Si highvoltage solar module prepared with 120 cells, we achieve an operation voltage of $100 \mathrm{~V}, \mathrm{FF}$ of $63.9 \%$, and conversion efficiency of $8.42 \%$. Particularly, the output power reaches a value of $1 \mathrm{~mW}$ when 120 cells are connected to form the high-voltage module. As shown in Figure 3(d), the maximum power and the operation voltage increase linearly with an increase in the number of interconnected microcells. On comparing with the photovoltaic characteristics of a single a-Si solar cell, no noticeable degradation in the FF and the operation voltage can be observed. Moreover, the fabrication of the whole device with diverse shapes and sizes even in a small area of about $2 \times 2 \mathrm{~cm}^{2}$ can be easily carried out by employing photolithography techniques. A high areal density and an enhanced operation voltage are achieved without inducing any additional structural changes, such as by using a parallel structure or interdigital electrodes, which were employed in the high-voltage power supplies made of organic solar cells.

Furthermore, we expect that the a-Si high-voltage solar module could be used for fabricating integrated photovoltaic (BIPV) systems [16]. The transmittance and the shapes of the module patterns can be controlled using photolithographic techniques. Besides, the high-voltage applications of the solar cells compensate the power loss of the solar cells induced by the sheet resistance of the transparent conductive oxide (TCO) such as indium tin oxide (ITO) [7, 10]. As a result, the fabrication of semitransparent high-voltage solar module can be realized without degrading the output power. Figure 4 shows the semitransparent property of the high-voltage solar module with $200 \mathrm{a}-\mathrm{Si}$ solar cells patterned in hundreds of micrometers prepared by photolithographic patterning. 


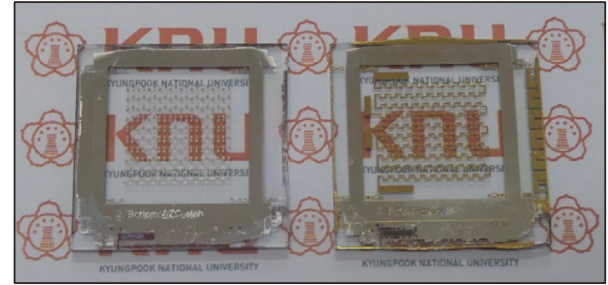

FIgURE 4: Photograph of a compact a-Si solar module for highvoltage power supply applications. It indicates the semitransparent characteristics of the individually micropatterned a-Si solar cells (left) and those serially interconnected with gold electrodes (right).

Except for the $\mathrm{Al}$ electrode, all layers in the a-Si solar cells exhibit relatively high transmittance. Even after depositing of gold electrodes, the high-voltage solar module exhibits semitransparent characteristics.

\section{Conclusion}

In this study, we fabricate compact a-Si solar modules for use as high-voltage power supplies. By employing photolithography techniques for patterning the solar module, we achieved a high areal density without any change of conventional fabrication methods comparing with the organic solar cells employing parallel solar cell structure or interdigital nanoelectrodes. Consequently, we achieved an operation voltage of $100 \mathrm{~V}, \mathrm{FF}$ of $63.9 \%$, conversion efficiency of $8.42 \%$, and maximum output power of $1 \mathrm{~mW}$ by connecting 120 solar cells in a small area, indicating outstanding photovoltaic properties as compared with the corresponding reported values. In addition, we expect to graft the compact a-Si solar module to a BIPV system to act as a power supply. The high transparency and the controllability of forming various patterns with inorganic material make the solar module suitable for smart window applications in BIPV [17]. The high open circuit voltage obtained without degrading the output power implies that the prepared solar module could be fascinating to be used in power supply applications.

\section{Competing Interests}

The authors declare that they have no competing interests.

\section{Acknowledgments}

This research was financially supported by the Ministry of Trade, Industry, and Energy (MOTIE), Republic of Korea, under the "Regional Specialized Industry Development Program (A015401181)" supervised by the Korea Institute for Advancement of Technology (KIAT). The authors also acknowledge support by the Fundamental Research Program (PNK4661) of the Korea Institute of Materials Science (KIMS).

\section{References}

[1] M. Karpelson, G.-Y. Wei, and R. J. Wood, "Driving high voltage piezoelectric actuators in microrobotic applications," Sensors and Actuators, A: Physical, vol. 176, pp. 78-89, 2012.

[2] M. Patrascu, J. Gonzalo-Ruiz, M. Goedbloed, S. H. Brongersma, and M. Crego-Calama, "Flexible, electrostatic microfluidic actuators based on thin film fabrication," Sensors and Actuators, A: Physical, vol. 186, pp. 249-256, 2012.

[3] M. Behnam, G. V. Kaigala, M. Khorasani, P. Marshall, C. J. Backhouse, and D. G. Elliott, "An integrated CMOS high voltage supply for lab-on-a-chip systems," Lab on a Chip-Miniaturisation for Chemistry and Biology, vol. 8, no. 9, pp. 1524-1529, 2008.

[4] K. A. Cook-Chennault, N. Thambi, and A. M. Sastry, "Powering MEMS portable devices-a review of non-regenerative and regenerative power supply systems with special emphasis on piezoelectric energy harvesting systems," Smart Materials and Structures, vol. 17, no. 4, Article ID 043001, 2008.

[5] F. Stelzl, J. Schulz-Gericke, M. Niggemann, and U. Würfel, "High yield fabrication of vertical interdigital electrodes with sub micrometer distance and their application in an organic photovoltaic device," Organic Electronics: Physics, Materials, Applications, vol. 14, no. 2, pp. 535-541, 2013.

[6] R. Garcia-Valverde, J. A. Villarejo, M. Hösel et al., "Scalable single point power extraction for compact mobile and standalone solar harvesting power sources based on fully printed organic photovoltaic modules and efficient high voltage DC/DC conversion," Solar Energy Materials and Solar Cells, vol. 144, pp. 48-54, 2016.

[7] M. Niggemann, B. Zimmermann, J. Haschke, M. Glatthaar, and A. Gombert, "Organic solar cell modules for specific applications-from energy autonomous systems to large area photovoltaics," Thin Solid Films, vol. 516, no. 20, pp. 7181-7187, 2008.

[8] J. Lewis, J. Zhang, and X. Jiang, "Fabrication of organic solar array for applications in microelectromechanical systems," Journal of Renewable and Sustainable Energy, vol. 1, no. 1, Article ID 013101, 2009.

[9] Y.-F. Lim, J.-K. Lee, A. A. Zakhidov et al., "High voltage polymer solar cell patterned with photolithography," Journal of Materials Chemistry, vol. 19, no. 30, pp. 5394-5397, 2009.

[10] M. Niggemann, W. Graf, and A. Gombert, "Realization of ultrahigh photovoltages with organic photovoltaic nanomodules," Advanced Materials, vol. 20, no. 21, pp. 4055-4060, 2008.

[11] A. J. Baca, K. J. Yu, J. Xiao et al., "Compact monocrystalline silicon solar modules with high voltage outputs and mechanically flexible designs," Energy and Environmental Science, vol. 3, no. 2, pp. 208-211, 2010.

[12] J. Yoon, A. J. Baca, S.-I. Park et al., "Ultrathin silicon solar microcells for semitransparent, mechanically flexible and microconcentrator module designs," Nature Materials, vol. 7, no. 11, pp. 907-915, 2008.

[13] K. L. Chopra, P. D. Paulson, and V. Dutta, “Thin-film solar cells: an overview," Progress in Photovoltaics: Research and Applications, vol. 12, no. 2-3, pp. 69-92, 2004.

[14] M. Schaper, J. Schmidt, H. Plagwitz, and R. Brendel, " $20.1 \%$ Efficient crystalline silicon solar cell with amorphous silicon rear-surface passivation," Progress in Photovoltaics: Research and Applications, vol. 13, no. 5, pp. 381-386, 2005.

[15] M. A. Green, K. Emery, Y. Hishikawa, W. Warta, and E. D. Dunlop, "Solar cell efficiency tables (Version 45)," Progress in Photovoltaics: Research and Applications, vol. 23, no. 1, pp. 1-9, 2015. 
[16] G. K. Singh, "Solar power generation by PV (photovoltaic) technology: a review," Energy, vol. 53, pp. 1-13, 2013.

[17] H.-K. Kwon, K.-T. Lee, K. Hur et al., "Optically switchable smart windows with integrated photovoltaic devices," Advanced Energy Materials, vol. 5, no. 3, Article ID 1401347, 2015. 

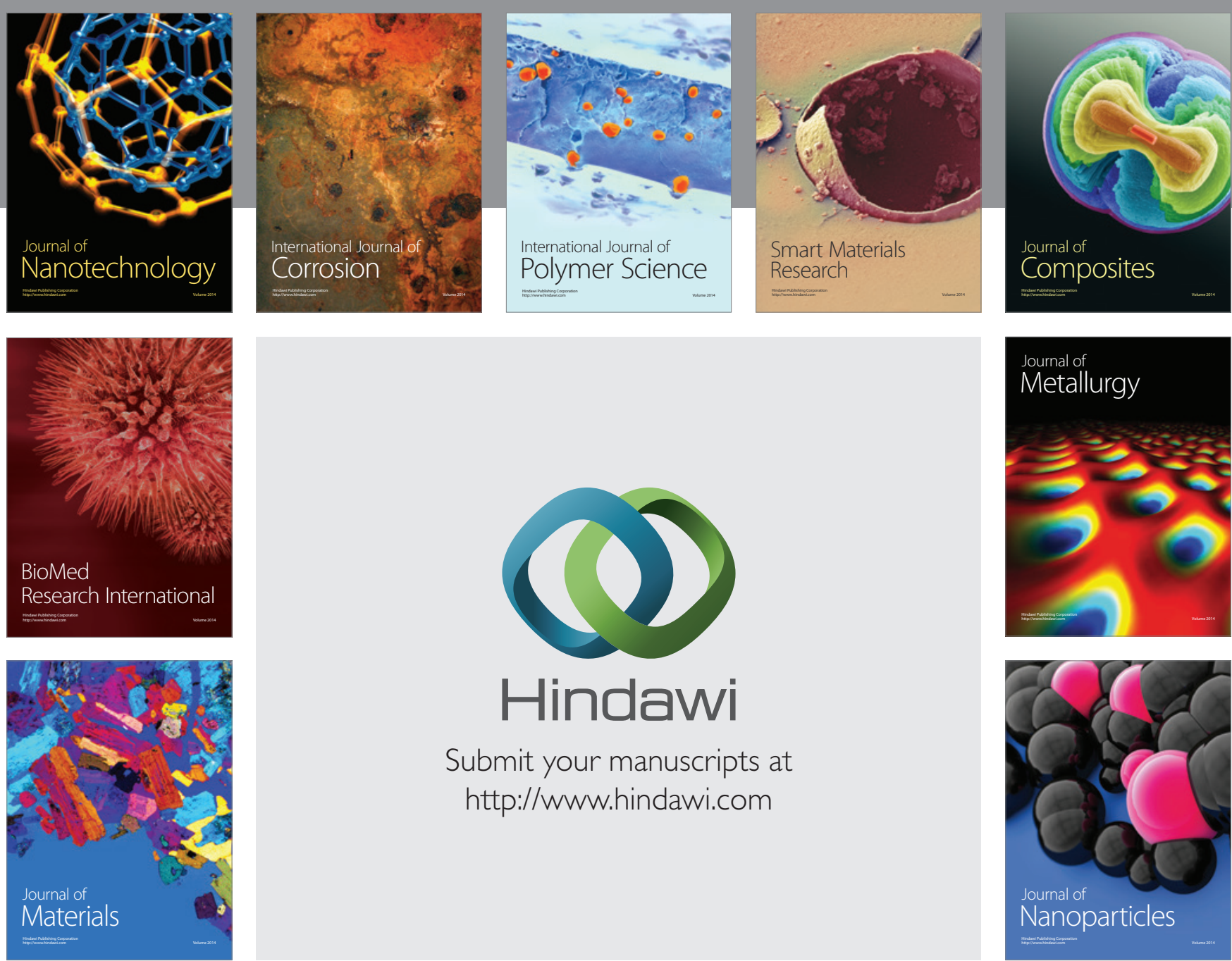

\section{Hindawi}

Submit your manuscripts at

http://www.hindawi.com

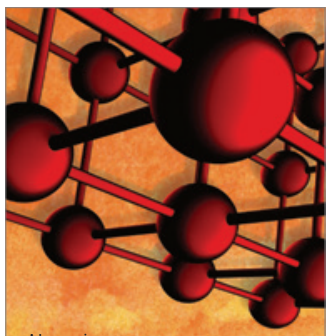

Materials Science and Engineering
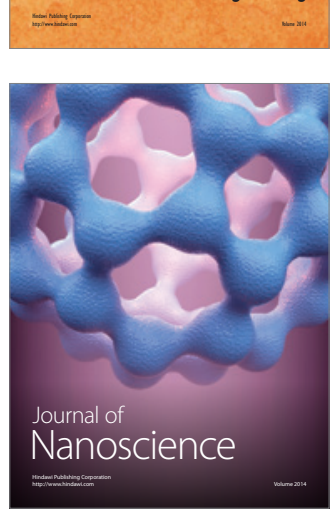
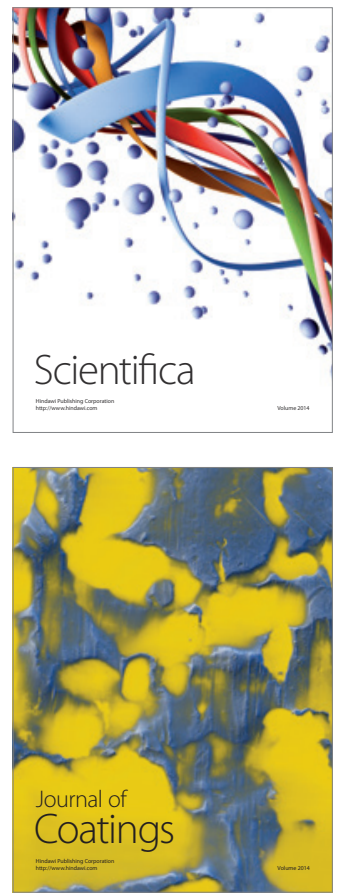
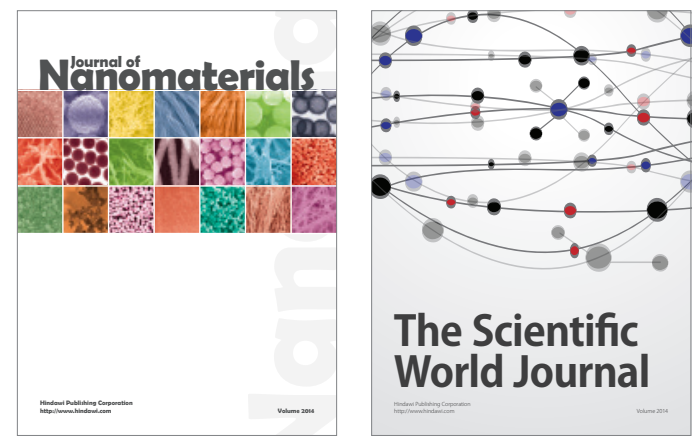

The Scientific World Journal
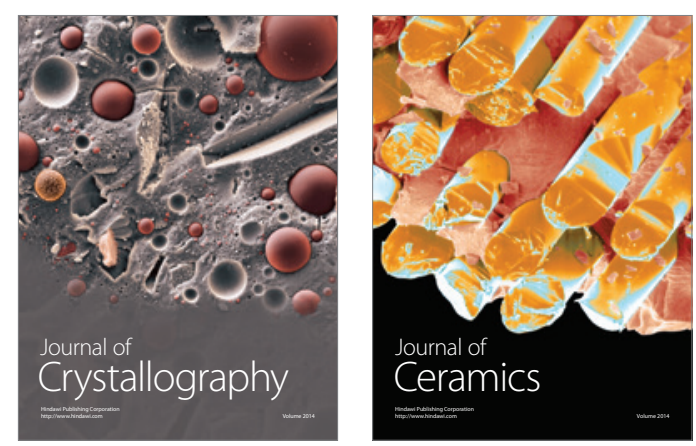
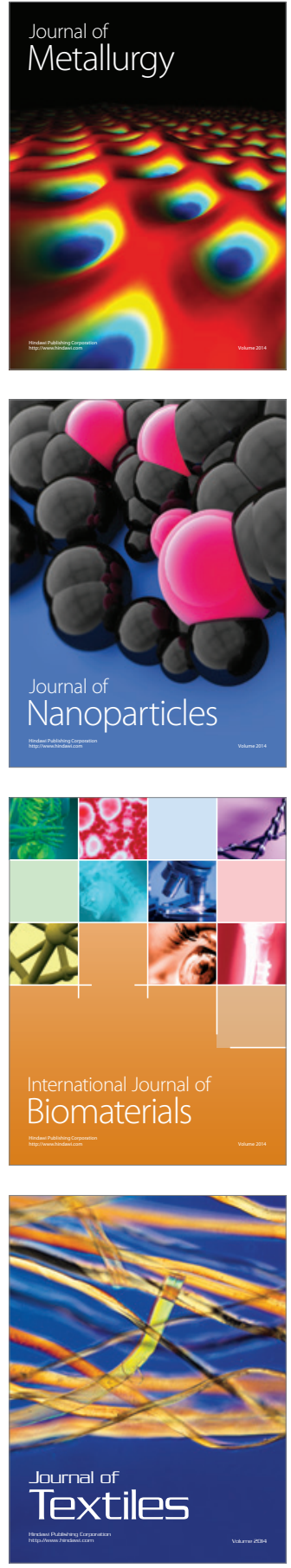